\title{
Desempenho produtivo e custos com alimentação de búfalas lactantes submetidas a dietas com diferentes fontes de lipídeo ${ }^{1}$
}

\author{
Ronaldo Lopes Oliveira', Adriana Regina Bagaldo², Márcio Machado Ladeira ${ }^{3}$, Marco Aurélio \\ Alves de Freitas Barbosa ${ }^{4}$, Renata Lopes de Oliveira ${ }^{5}$, Gabriel Jorge Carneiro de Oliveira ${ }^{6}$ \\ ${ }^{1}$ DPA/UFBA. Av. Ademar de Barros, 500, Ondina, CEP: 401170-110, Salvador-BA, Tel.: (71) 3283-6716. FAX: (71) 3283-6716. \\ 2 Bolsista PRODOC/DCR - FAPESB/CNPq, DPA/UFBA, Salvador-BA. \\ ${ }^{3}$ DZO/UFLA, Lavras-MG. \\ ${ }^{4}$ DZO/UEL, Londrina-PR. \\ 5 Curso de Zootecnia da UPIS, Brasília-DF. \\ ${ }^{6}$ CCAA/UFRB, Cruz das Almas-BA.
}

RESUMO - Objetivou-se avaliar o desempenho de búfalas lactantes alimentadas com diferentes fontes de lipídeo. Utilizaram-se 12 búfalas distribuídas aleatoriamente em quatro tratamentos: sem lipídeo adicional; grão de soja; caroço de algodão; e óleo de soja. O período experimental total foi de 84 dias, com quatro períodos de 21 dias (14 dias para a adaptação e 7 para coleta). A dieta foi fornecida à vontade, duas vezes ao dia, na forma de mistura completa. Nos dias de coleta de cada período, foram determinadas as produções de leite em $\mathrm{kg} / \mathrm{dia}$ e as produções ajustadas para $4 \%$ de gordura. Foram coletados $4 \mathrm{~kg}$ de lete para produção de queijo tipo mussarela. Após a elaboração da mussarela, determinou-se o rendimento em relação ao leite in natura e corrigido para $4 \%$ de gordura. As fontes de lipídeo não influenciaram a produção diária de leite das búfalas, mas afetaram a produção de leite corrigida para $4 \%$ de gordura, que foi maior nas búfalas que receberam a dieta com grão de soja. O rendimento do leite para produção de mussarela foi maior quando fornecida a dieta com óleo de soja. Os custos de alimentação, por dia e total (84 dias), foram maiores para a dieta com caroço de algodão, seguida da dieta com óleo de soja e pelas dietas sem lipídeos adicionais e com grão de soja. A lucratividade com a venda do leite foi maior para a dieta com grão de soja, com óleo de soja, sem lipídio adicional e com caroço de algodão, respectivamente, e com a venda de mussarella foi maior para a dieta com óleo de soja. Como o principal produto do leite de búfala é a mozzarella, os resultados sugerem que das dietas estudadas, aquela com óleo de soja seria a mais adequada para a alimentação de búfalas leiteiras.

Palavras-chave: caroço de algodão, extrato etéreo, grão de soja, lactação, óleo de soja

\section{Performance and feed cost of lactating water buffalo cows fed different fat sources}

\begin{abstract}
The objective was to evaluate the performance of lactating water buffalo fed diets with different fat sources. Twelve lactating water buffaloes were randomly distributed in four diets: without additional fat, soybean seed, cottonseed and soybean oil. The experimental period was 84 days, with four periods of 21 days (14 days for diet adaptation and 7 days for sample collections. The diets were fullfed, twice daily, as total mixed ration. At sample collections period, milk yield $(\mathrm{kg} / \mathrm{day})$ and $4 \%$ fat corrected milk (4\%FCM) yield were evaluated. Four kg of milk were collected for mozzarella type cheese production. After mozzarella cheese production, it was determined the efficiency in relation to milk in natura and milk 45FCM. The fat sources did not affect daily milk production of water buffalo cows, however affected the $4 \% \mathrm{FCM}$, which was higher in the water buffalo cows that was fed diet with soybean seed. The efficiency of milk for Mozzarella production was higher for soybean oil diet. Feeding costs, per day and total (84 days) were higher for the diet with cottonseed, followed by soybean oil, without additional fat and soybean seed. The profitability for the milk sale was higher for diet with soybean grain, soybean oil, without additional lipid and with cottonseed, respectively, and for mozzarella sail was higher for soybean oil. As the main buffalo milk product is the mozzarella, results suggested that the diet with soybean oil content would be the best for lactating water buffalo.
\end{abstract}

Key Words: cottonseed, ether extract, lactation, soybean grain, soybean oil

\section{Introdução}

A produção de leite de búfalas é uma atividade de grande importância em muitos países do mundo. No Brasil, o búfalo tem despertado interesse crescente de criadores e órgãos de pesquisa por ser alternativa na pecuária leiteira (Jorge et al., 2006).

O leite de búfala difere do leite de vaca pelos maiores teores de proteína, gordura, lactose e minerais, como cálcio e fósforo (Dubey, 1996). A industrialização do leite de

Este artigo foi recebido em 24/9/2007 e aprovado em 21/2/2008.

Correspondências devem ser enviadas para ronaldooliveira@ufba.br. 
búfalas produz alimentos diferenciados, como queijo mussarela e provolone, ricota, entre outros, que normalmente recebem remuneração superior à de produtos do leite bovino (Jorge et al., 2006).

Segundo Freire Filho (1995), na década de 1990, o número de laticínios que operam exclusivamente com o leite de bubalinos aumentou significativamente. Além disso, surgiram pequenas bacias leiteiras dedicadas à industrialização do leite de búfalas. Pelo fato de a búfala ter produtividade limitada, o aumento da quantidade de leite produzido, com mesma qualidade e composição, possibilita maior rentabilidade para os produtores.

A utilização de alimentos ricos em lipídeos na alimentação animal tem se tornado cada vez mais comum quando se busca aumentar a produtividade animal. Os lipídeos são fontes com alta concentração de energia prontamente disponível, pois são constituídos de grande proporção de ácidos graxos. Segundo Sutton (1989), a suplementação lipídica em níveis de 6 a 8\% na matéria seca (MS) da dieta resulta em aumentos na produção de leite. Contudo, em vários estudos encontrados na literatura com diferentes fontes de lipídeos, essas respostas foram contraditórias (Mielke \& Schingoethe, 1980; Faldet \& Satter, 1991; Dhiman et al., 1999). Além disso, pouco se conhece sobre o retorno econômico da utilização dessas fontes de lipídeos nas espécies de ruminantes.

A resposta na produção de gordura também é variável, pois depende da forma física e da composição dos ácidos graxos suplementados. Sempre que ocorrem alterações no tipo de dieta com o uso de oleaginosas ou óleos, deve-se considerar que o tipo de dieta altera o perfil de ácidos do leite de ruminantes (French et al., 2000). Grummer (1991) descreveu que a inclusão de óleo de canola e de girassol em dietas para vacas em lactação pode reduzir a concentração de ácidos graxos de cadeia curta e aumentar a porcentagem de ácidos graxos de cadeia longa. Caso isto ocorra em búfalas, dependendo da intensidade, poderá ocorrer redução na produção de gordura no leite.

Objetivou-se com este trabalho avaliar a produção de leite e os custos com alimentação em búfalas alimentadas com dietas contendo diversas fontes de lipídeos.

\section{Material e Métodos}

O experimento foi realizado na Fazenda Lagoa Bonita, Campus Rural das Faculdades Integradas UPIS, localizada em Planaltina, DF. Foram utilizadas 12 búfalas em lactação, multíparas, com peso vivo (PV) de $683 \pm 17 \mathrm{~kg}$ e produção média diária de leite de $6,5 \mathrm{~kg}$, no período de setembro a dezembro de 2003.
Tabela 1 - Composição das dietas experimentais, \% da MS

\begin{tabular}{lcccc}
\hline $\begin{array}{l}\text { Componente } \\
\text { (\%MS) }\end{array}$ & \multicolumn{4}{c}{$\begin{array}{c}\text { Fonte de lipídeo } \\
\text { utilizada na dieta }\end{array}$} \\
\cline { 2 - 5 } & $\begin{array}{c}\text { Sem lipídeo } \\
\text { adicional }\end{array}$ & $\begin{array}{c}\text { Grão de } \\
\text { soja }\end{array}$ & $\begin{array}{c}\text { Óleo de } \\
\text { soja }\end{array}$ & $\begin{array}{c}\text { Caroço de } \\
\text { algodão }\end{array}$ \\
\hline Silagem de milho & 70,00 & 75,00 & 74,72 & 70,83 \\
Milho grão moído & 15,94 & 8,58 & 8,33 & 12,92 \\
Farelo de soja & 12,03 & 1,89 & 12,70 & 11,67 \\
Grão de soja & - & 12,50 & - & - \\
Óleo de soja & - & - & 2,21 & - \\
Caroço de algodão & - & - & - & 2,50 \\
Calcário & 0,31 & 0,31 & 0,31 & 0,33 \\
Fosfato bicálcico & 1,72 & 1,72 & 1,72 & 1,75 \\
\hline Item (\%MS) & & & & \\
\hline Proteína bruta & 11,89 & 12,05 & 11,96 & 12,09 \\
Fibra em & 41,40 & 44,60 & 42,72 & 42,32 \\
detergente neutro & & & & \\
Fibra em & 28,29 & 31,09 & 28,61 & 28,84 \\
detergente ácido & & & & 3,10 \\
Extrato etéreo & 2,76 & 4,34 & 4,85 & 33,82 \\
Carboidratos & 35,45 & 30,28 & 31,68 & 3,79 \\
não-fibrosos & & & & \\
Cinzas & 8,51 & 8,73 & 8,79 & \\
\hline
\end{tabular}

Antes do experimento, os animais foram pesados, tratados contra ecto e endoparasitos e distribuídos aleatoriamente em quatro tratamentos: sem lipídeo adicional; grão de soja; óleo de soja; e caroço de algodão. O volumoso foi incluído nas dietas em quantidades de 70 e $75 \%$ e foi constituído de silagem de milho (Tabela 1). O período experimental foi de 84 dias, divididos em quatro subperíodos de 21 dias: 14 dias para a adaptação dos animais às dietas e 7 dias para coleta.

Os animais foram alojados em baias individuais providas de cochos para ração, suplemento mineral e bebedouros. A dieta foi fornecida à vontade, na forma de mistura completa, duas vezes ao dia, logo após as ordenhas das 5 e 16 h. A pesagem das sobras foi feita diariamente pela manhã a fim de se ajustar a quantidade de ração ministrada para que os animais deixassem resíduo diário de 10 a $20 \%$ do total fornecido.

Nos sete dias de coleta de cada período, foram medidas as produções de leite em $\mathrm{kg} / \mathrm{dia}$ e ajustadas para $4 \%$ de gordura, conforme equação proposta por Gaines \& Davidson (1925): leite corrigido a $4 \%$ gordura $(4 \% \mathrm{G})=(0,4 \times \mathrm{PL})+$ $(0,15 \times \mathrm{PL} \times \mathrm{G} \%)$, em que: $\mathrm{PL}=$ produção de leite em kg/dia; e $\mathrm{G} \%=$ porcentagem de gordura do leite. Foram coletados $4 \mathrm{~kg}$ de leite por dia, que foram armazenados a $-20^{\circ} \mathrm{C}$ para produção de mussarela. Posteriormente, realizaram-se os cálculos de rendimento do leite e do leite corrigida para $4 \%$ de gordura e corrigido por kg de mussarela. 
Nesse mesmo período, diariamente, amostras dos alimentos fornecidos e das sobras foram coletadas para análise dos teores de MS, proteína bruta (PB) e extrato etéreo (EE), segundo metodologia descrita pela AOAC (1990); e fibra em detergente neutro (FDN) e fibra em detergente ácido (FDA), segundo Van Soest et al. (1991). Os teores de carboidratos não-fibrosos (CNF) foram calculados de acordo com Mertens (1987), em que: $\mathrm{CNF}=100-(\mathrm{FDN}+\mathrm{PB}+\mathrm{EE}+$ Cinzas $)$.

Os consumos de MS e de cada nutriente foram calculados subtraindo-se os valores encontrados nas sobras daqueles existentes na ração fornecida. O consumo de NDT (CNDT) e os teores de nutrientes digestíveis totais (NDT\%) foram calculados segundo Sniffen et al. (1992), utilizando-se as equações: $\mathrm{CNDT}=(\mathrm{PB}$ ing. $-\mathrm{PB}$ fecal $)+2,25$ (EE ing. EE fecal $)+($ CHT ing. - CHT fecal $)$ e NDT $(\%)=($ Consumo de NDT / Consumo de MS) $\times 100$ ). Os dados foram utilizados para determinação da conversão alimentar, calculada pela razão entre o consumo $(\mathrm{kg})$ de $\mathrm{MS}, \mathrm{PB}, \mathrm{FDN}$ e NDT e a produção $(\mathrm{kg})$ de leite e de leite corrigido para $4 \%$ de gordura.

Os custos com alimentação foram calculados considerando os preços de cada ingrediente no mercado de Brasília, Distrito Federal, no segundo semestre de 2003.

$\mathrm{O}$ delineamento experimental foi de três quadrados latinos simultâneos $(4 \times 4)$, cada um com quatro animais, quatro períodos e quatro dietas. Os dados foram analisados estatisticamente pelo SAEG (UFV, 1997) aplicando-se o teste Tukey a $5 \%$ de probabilidade. Na análise dos custos com alimentação, não foram utilizadas comparações estatísticas, pois os custos se referiam ao grupo total de animais.

\section{Resultados e Discussão}

A produção de leite das búfalas variou de 6,4 a 7,2 kg/dia. Entretanto, as fontes de lipídeos utilizadas não influenciaram ( $>0,05)$ esta característica (Figura 1). Segundo McGuire et al. (1996), a inclusão de lipídeo em níveis de até 7\% na dieta de vacas leiteiras não afeta a produção de leite. Neste trabalho, as dietas apresentaram no máximo 4,85\% de EE (Tabela 1). Ao corrigir o leite para $4 \%$ de gordura, quando fornecida a dieta com grão de soja, as búfalas apresentaram maior produção (kg/dia) (Figura 1). Não foram encontrados trabalhos nos quais a produção de leite corrigida para $4 \%$ de gordura, em vacas leiteiras, tenha aumentado com a inclusão de alguma fonte de lipídeo na dieta.

Outros autores (Grant \& Weidner, 1992; McGuire et al., 1996; Rabello et al., 1996; Santos et al., 2001; Vargas, 2002) também não verificaram diferenças na produção e compo-
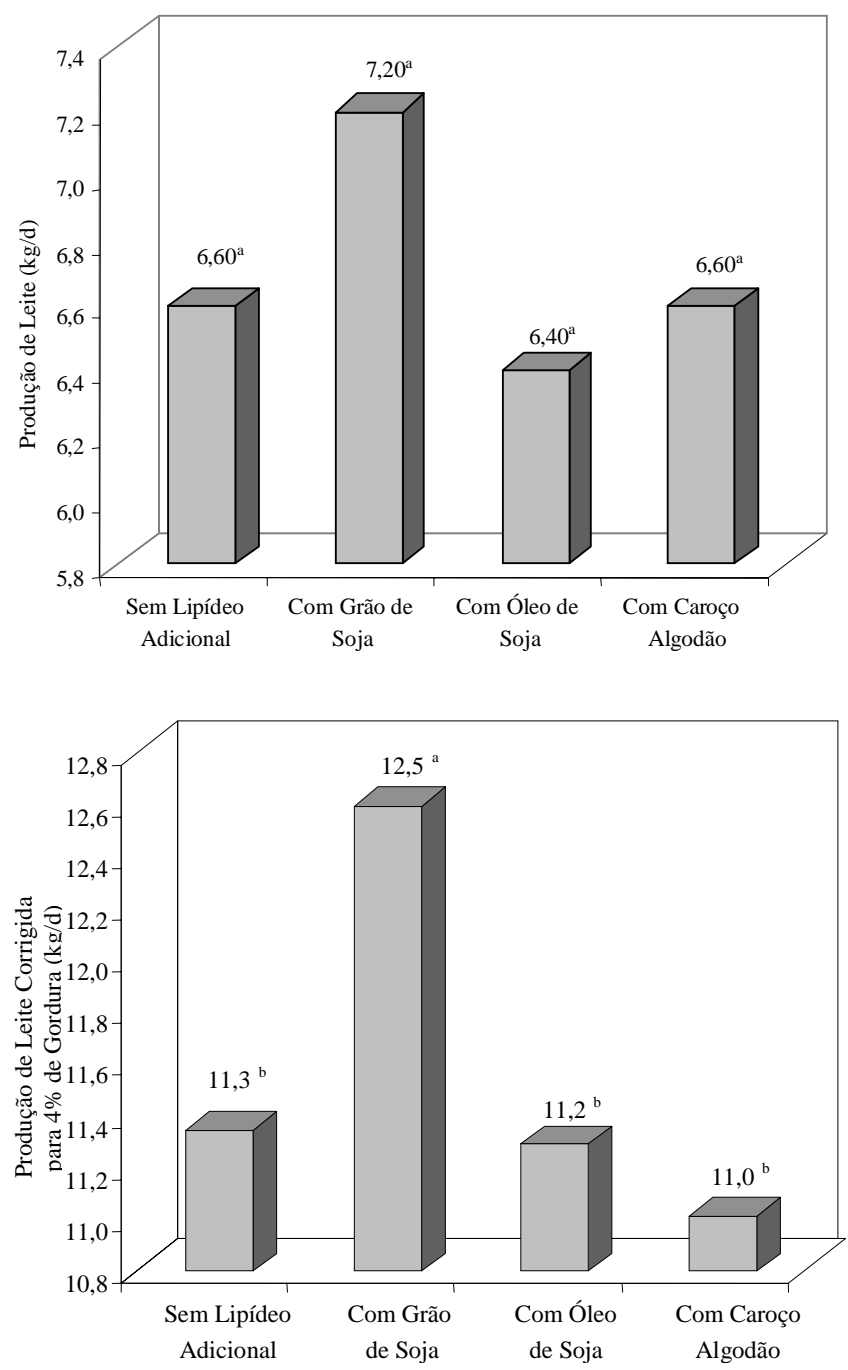

a, b Médias nas linhas seguidas por letras iguais não diferem entre si pelo teste Tukey (5\%).

Figura 1 - Produção de leite (kg/dia) e produção de leite corrigida para $4 \%$ de gordura $(\mathrm{kg} / \mathrm{dia})$ de búfalas alimentadas com dietas com diferentes fontes de lipídeo.

sição de leite de vacas alimentadas com dietas contendo grão ou óleo de oleaginosas, em níveis de até 7\% de EE. Entretanto, Mora et al. (1996) relataram que vacas alimentadas com ração com $45 \%$ de grão de soja no concentrado produziram $17,7 \%$ menos leite corrigido para $4 \%$ de gordura em comparação a vacas alimentadas com rações sem grão de soja. Do mesmo modo, Silva (1997) encontrou menor produção de leite e produção de leite corrigida para 3,5\% de gordura quando forneceram $30 \%$ de grão de soja cru moído no concentrado. Respostas negativas na produção de leite de vacas em lactação sob suplementação lipídica também foram observadas por Eifert et al. (2005). As menores produções de leite corrigidas podem ser explicadas pelo aumento 

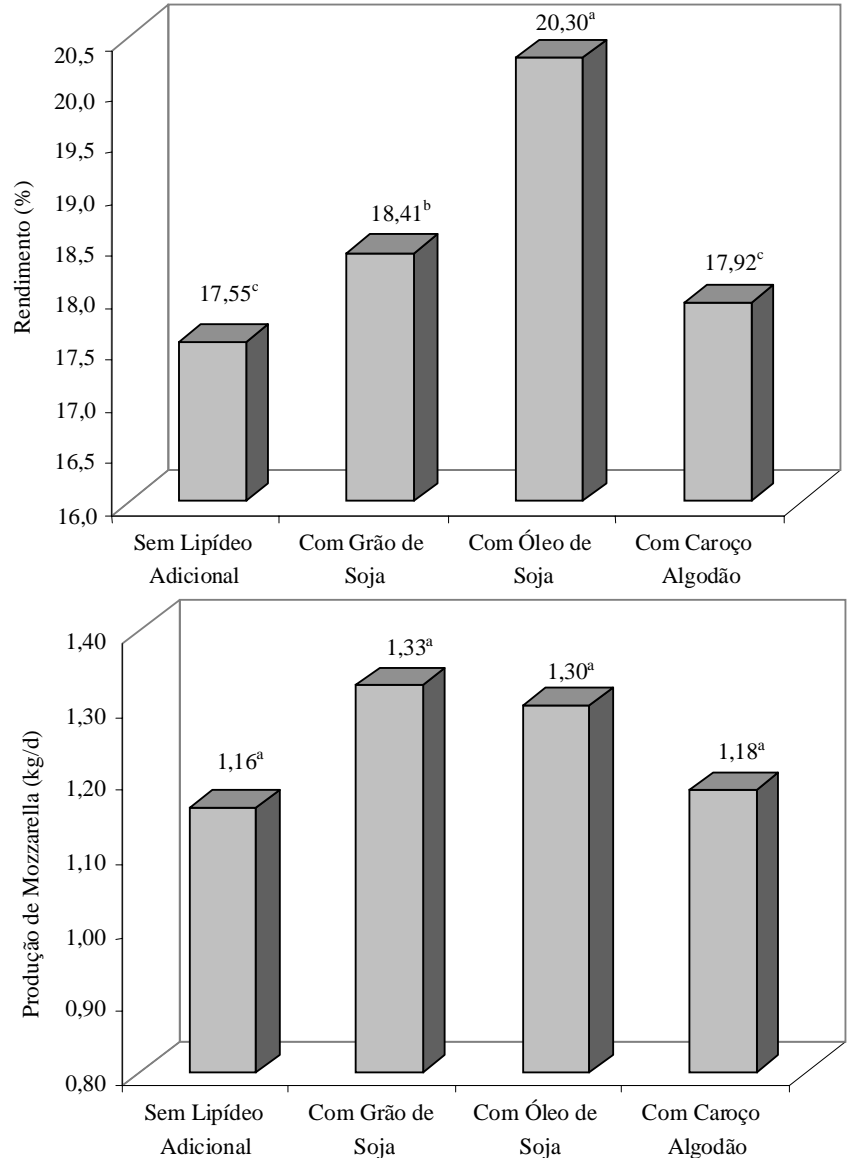

a, b, c Médias nas linhas seguidas de letras iguais não diferem entre si pelo teste Tukey (5\%).

Figura 2 - Rendimento (\%) e produção (kg/dia) de mussarela em búfalas alimentadas com dietas contendo diferentes fontes de lipídeo. na concentração de ácidos graxos trans- no rúmen, que, depois de absorvidos no intestino delgado, inibem a síntese de novo de ácidos graxos na glândula mamária. Todavia, esse efeito é potencializado quando os animais recebem altas quantidades de concentrado na dieta, muito comum em sistemas de produção de bovinos. Provavelmente, a suplementação com grão de soja promoveu maior absorção de ácidos graxos dietéticos, que foram secretados na gordura do leite.

A possibilidade de os ácidos graxos sofrerem biohidrogenação também influencia a produção de ácidos trans- e pode explicar a ausência de efeito da suplementação com óleo de soja, em relação à não-suplementação com fontes de lipídeo, apesar da maior absorção intestinal de ácidos graxos.

Orendimento de mussarela $(\%)$ foi maior $(\mathrm{P}<0,05)$ quando fornecida a dieta com óleo de soja (Figura 2), enquanto a produção de mussarela $(\mathrm{kg} / \mathrm{dia})$ foi semelhante entre as dietas $(\mathrm{P}>0,05)$. A composição lipídica do leite, principalmente de búfalas, é uma das características de maior importância na determinação da qualidade comercial do produto, pois está relacionada à produção de queijo. Segundo Altiero et al. (1989), os dois principais fatores que influenciam a produção de mussarela é o teor de proteína e gordura do leite. Neste trabalho, a dieta com óleo de soja apresentou maior teor de gordura $(\mathrm{P}<0,05)$, mas não diferiu das demais quanto aos teores de proteína. Esses autores propuseram uma equação de predição de produção de queijo de rebanhos italianos de búfalos nas qual os fatores considerados são a proteína e a gordura, o que confirma a importância da

Tabela 2 - Conversão alimentar ( $\mathrm{kg}$ alimento consumido/kg leite produzido) em búfalas alimentadas com dietas contendo diversas fontes de lipídeo

\begin{tabular}{|c|c|c|c|c|c|}
\hline \multirow[t]{2}{*}{ Conversão alimentar $(\mathrm{kg} / \mathrm{kg})$} & \multicolumn{4}{|c|}{ Fonte de lipídeo utilizada na dieta } & \multirow[t]{2}{*}{$\mathrm{CV}(\%)$} \\
\hline & Sem lipídeo adicional & Grão de soja & Óleo de soja & Caroço de algodão & \\
\hline \multicolumn{6}{|c|}{ Considerando a produção de leite diária } \\
\hline Matéria seca & $1,34 \mathrm{a}$ & $1,17 \mathrm{~b}$ & $1,44 \mathrm{a}$ & $1,37 \mathrm{a}$ & 36,78 \\
\hline Fibra em detergente neutro & 0,59 & 0,59 & 0,66 & 0,62 & 36,63 \\
\hline Proteína bruta & 0,17 & 0,15 & 0,19 & 0,18 & 36,69 \\
\hline Nutrientes digestíveis totais & 1,01 & 0,91 & 1,08 & 0,95 & 38,47 \\
\hline \multicolumn{6}{|c|}{ Considerando a produção de leite corrigida para $4 \%$ de gordura } \\
\hline Matéria seca & $0,78 \mathrm{a}$ & $0,67 \mathrm{~b}$ & $0,82 \mathrm{a}$ & $0,82 \mathrm{a}$ & 27,15 \\
\hline Fibra em detergente neutro & 0,34 & 0,34 & 0,37 & 0,37 & 29,01 \\
\hline Proteína bruta & 0,10 & 0,09 & 0,11 & 0,11 & 23,10 \\
\hline Nutrientes digestíveis totais & 0,59 & 0,52 & 0,61 & 0,57 & 21,07 \\
\hline \multicolumn{6}{|c|}{ Considerando a produção de mussarela } \\
\hline Matéria seca & 7,64 & 6,36 & 7,09 & 7,65 & 32,05 \\
\hline Fibra em detergente neutro & 3,36 & 3,20 & 3,25 & 3,46 & 26,31 \\
\hline Proteína bruta & 0,97 & 0,81 & 0,94 & 1,00 & 24,12 \\
\hline Nutrientes digestíveis totais & 5,75 & 4,94 & 5,32 & 5,30 & 23,64 \\
\hline
\end{tabular}


Tabela 3 - Avaliação dos custos e da receita em relação à produção de leite

\begin{tabular}{|c|c|c|c|c|}
\hline \multirow[t]{2}{*}{ Item } & \multicolumn{4}{|c|}{ Fonte de lipídeo utilizada na dieta } \\
\hline & Sem lipídeo adicional & Grão de soja & Óleo de soja & Caroço de algodão \\
\hline Custo com alimentação/animal/dia ( $\mathrm{R} \$)$ & 2,87 & 2,84 & 2,96 & 3,12 \\
\hline Dias de confinamento & 84,00 & 84,00 & 84,00 & 84,00 \\
\hline Custo com alimentação total ( $\mathrm{R} \$ / 84$ dias) & 240,81 & 238,61 & 248,63 & 261,86 \\
\hline Produção média de leite diária (kg/animal) & 6,60 & 7,20 & 6,80 & 6,60 \\
\hline Produção total (kg/animal) & 554,40 & 604,80 & 571,20 & 554,40 \\
\hline Preço recebido por $\mathrm{kg}$ de leite $(\mathrm{R} \$)$ & 0,75 & 0,75 & 0,75 & 0,75 \\
\hline Preço recebido/produção total $(\mathrm{R} \$)$ & 415,80 & 453,60 & 428,40 & 415,80 \\
\hline Margem bruta da venda do leite ( $\mathrm{R} \$$ /animal) & 174,99 & 214,99 & 179,77 & 153,94 \\
\hline
\end{tabular}

Tabela 4 - Avaliação dos custos e da receita considerando a produção e o rendimento de mussarela

\begin{tabular}{lcrrr}
\hline Item & \multicolumn{3}{c}{ Fonte de lipídeo utilizada na dieta } \\
\cline { 2 - 5 } & Sem lipídeo adicional & Grão de soja & Óleo de soja & Caroço de algodão \\
\hline Rendimento em mussarela (\%) & 17,55 & 18,41 & 20,30 & 17,92 \\
Mussarela produzida (kg) & 97,30 & 111,34 & 115,95 & 99,35 \\
Preço recebido/kg mussarela (R\$) & 15,00 & 15,00 & 15,00 & 15,00 \\
Preço recebido/produção total de mussarela (R\$) & $1.459,46$ & $1.670,16$ & $1.739,30$ & $1.490,23$ \\
Margem bruta com venda da mussarela (R\$/animal) & $1.218,64$ & $1.431,55$ & $1.490,68$ & $1.228,37$ \\
\hline
\end{tabular}

maior fração lipídica do leite desses animais em comparação ao leite de bovinos.

Búfalas que receberam a dieta contendo grão de soja como fonte lipídica apresentaram a melhor conversão alimentar (Tabela 2) calculada em relação à produção de leite diária e corrigida para $4 \%$ de gordura. A maior produção de leite (kg/dia) das búfalas alimentadas com a dieta suplementada com grão de soja (Figura 1) pode ter contribuído para essa melhor conversão alimentar.

Os custos de alimentação/animal/dia e total (84 dias) foram maiores quando fornecida a dieta com caroço de algodão, seguida daquelas com óleo de soja, sem lipídeo adicional e com grão de soja (Tabela 3). Ao considerar o preço do leite de búfala comercializado, de $\mathrm{R} \$ 0,75$, observou-se que a maior margem bruta foi obtida para o leite produzido pelas búfalas que receberam a dieta com grão de soja. Essa resposta pode estar relacionada ao fato de esse grupo ter apresentado maior produção média de leite e menor custo de alimentação/animal/dia.

Entretanto, como o principal produto comercial do leite de búfala é a mussarela, deve-se realizar a avaliação econômica considerando a produção de mussarela (Tabela 4). Uma vez que o maior rendimento ocorreu quando as búfalas foram alimentadas com a dieta contendo óleo de soja, a receita obtida com a produção de mussarela desse grupo foi superior, o que resultou em margem bruta de $\mathrm{R} \$ 1.490,68$ por animal. Além disso, a menor margem bruta encontrada foi para a dieta sem lipídeo adicional, o que estaria mais perto da realidade brasileira, pois tradicionalmente a pecuária leiteira ainda não utiliza, ou utiliza pouco, a suplementação lipídica.

Este estudo foi realizado durante 84 dias. Considerando uma fazenda com 25 búfalas alimentadas com a dieta com óleo de soja, a produção mensal de leite seria de $5.400 \mathrm{~L}$, com custos de alimentação de R \$ 2.220,00 e margem bruta de R\$1.605,00. Ao calcular em relação à produção de mussarela, a margem bruta seria de $\mathrm{R} \$ 13.309,50$.

\section{Conclusões}

Entre as fontes de lipídeos estudadas, a que demonstrou utilização mais adequada foi o óleo de soja, visto que, apesar de não ser o tratamento que proporcionou a maior produção de leite, foi o que levou ao maior rendimento do leite em mozzarella, que é o principal produto comercial do leite de búfala.

\section{Literatura Citada}

Altiero, V.; MOIO, L.; ADDEO, F. Previsione della resa in mozzarela sulla base del contenuto in grasso e roteine del latte di bufala. Science Tecnology Latte, v.40, p.425-433, 1989.

ASSOCIATION OF ANALYTICAL CHEMISTS - AOAC. Official methods of analysis. 12.ed. Washington, D.C.: 1990. 1094p.

DHIMAN, T.R.; HELMINK, E.D.; McMAHON, D.F. et al. Conjugated linoleic acid of milk and cheese from cows fed extruded oilseeds. Journal of Dairy Science, v.82, n.10, p.412-419, 1999. 
DUBEY, P.C.; SUMAN, C.L.; SANYAL, M.K. et al. Factors affecting composition of milk of buffaloes. Journal of Animal Science, v.67, n.802-804, 1997.

FALDET, M.A.; SATTER, L.D. Feeding heat-treated full fat soybeans to cows to early lactation. Journal of Dairy Science, v.74, n.9, p.3047-3054, 1991.

FRENCH, P.; STANTON, C.; LAWLESS, F. et al. Fatty acid composition, including conjugated linoleic acid, of intramuscular fat from steers offered grazed grass, grass silage, or concentratebased diets. Journal of Animal Science, v.78, p.2849-2855, 2000.

FREIRE FILHO, R.A.B. Laticínio especializado cria primeira bacia exclusiva de leite de búfalas no País. Revista dos Criadores, v.65, p.3-6, 1995.

GAINES, W.L.; DAVIDSON, F.A. The effect of advance in lactation and gestation on mammary activity. The Journal of General Physiology, v.9, p.325-332, 1925.

GRANT, R.J.; WEIDNER, S.J. Effect of fat from whole soybeans on performance of dairy cows fed rations differing in the fiber level and particle size. Journal of Dairy Science, v.75, n.10, p.2742-2751, 1992.

EIFERT, E.C.; LANA, R.P.; LANNA, D.P.D. Efeitos do fornecimento de monensina e óleo de soja na dieta sobre o desempenho de vacas leiteiras na fase inicial da lactação. Revista Brasileira de Zootecnia, v.34, n.6, p.2123-2132, 2005.

GRUMMER, R.R. Effect of feed on the composition of milk fat. Journal of Dairy Science, v.74, n.9, p.3244-3257, 1991.

JorGE, A.M.; ANDRigheTto, C.; Millen, D.D. et al. Desempenho e eficiência biológica de bubalinos de três grupos genéticos terminados em confinamento e abatidos em diferentes estádios de maturidade. Revista Brasileira de Zootecnia v.35, p.252-257, 2006.

MCGUIRE, M.A.; MCGUIRE, M.K.; GUY, M.A. et al. Effect of dietary lipid concentration on content of conjugated linoleic acid (CLA) in milk from dairy cattle. Journal of Animal Science, v.74, p.266, 1996 (suppl. 1).

MERTENS, D.R. Predicting intake and digestibility using mathematical models of ruminal function. Journal of Animal Science, v.64, p.1548-1558, 1987.
MIELKE, C.D.; SCHINGOETHE, D.J. Heat-treated soybeans for lactating cows. Journal of Animal Science, v.65, p.15791585,1980

MORA, P.J.G.; LEÃO, M.I.; VALADARES FILHO, S.C. et al. Grão de soja em rações para vacas lactantes: consumo dos nutrientes, produção e composição do leite. Revista Brasileira de Zootecnia, v.25, p.369-381, 1996.

RABELLO, T.M.; VALADARES FILHO, S.C.; COELHO DA SILVA, J.F. et al. Grão de soja moído na alimentação de vacas em lactação. I. Consumos, produção e composição do leite. Revista Brasileira de Zootecnia, v.25, p.345-356, 1996.

SANTOS, F.L.; LANA, R.P.; SILVA, M.T.C. et al. Produção e composição do leite de vacas submetidas a dietas contendo diferentes níveis e formas de suplementação de lipídeos. Revista Brasileira de Zootecnia, v.30, p.1376-1380, 2001.

SILVA, C.M.A.P. Produção e composição do leite, variação de peso corporal e digestibilidade em vacas alimentadas com ração contendo grão de soja moído no concentrado. Viçosa, MG: Universidade Federal de Viçosa, 1997. 72p. Dissertação (Mestrado em Zootecnia) - Universidade Federal de Viçosa, 1997.

SNIFFEN, C.J.; O CCONNOR, J.D.; Van SOEST, P.J. et al. A net carboydrate and protein systein for evaluating cattle diets: II. Carbohydrate and protein availability. Journal of Animal Science, v.70, p.3562-3577, 1992.

SUTTON, J.D. Altering milk composition by feeding. Journal of Dairy Science, v.72, n.10, p.2801-2814, 1989.

UNIVERSIDADE FEDERAL DE VIÇOSA - UFV. SAEG - Sistema de Análise Estatística e Genética. Viçosa, MG: 1997. (CD-ROM).

Van SOEST, P.J.; ROBERTSON, J.B.; LEWIS, B.A. et al. Methods for dietary fiber, and non-starch polysaccharides in relation to animal nutrition. Journal of Dairy Science, v.74, p.3583$3597,1991$.

VARGAS, L.H.; LANA, R.P.; JHAM, G.N. et al. Adição de lipídeos na ração de vacas leiteiras: parâmetros fermentativos ruminais, produção e composição do leite. Revista Brasileira de Zootecnia, v.31, p.522-529, 2002. 